\title{
Penilaian Kuat Tekan Beton pada Struktur Mushola Nurus Sa'ada Tangerang
}

\author{
Eko Darma ${ }^{1}$, Anita Setyowati Srie Gunarti ${ }^{1, *}$, Dian Ekawati ${ }^{1}$, Inna Ekawati ${ }^{1}$, Sri Nuryati ${ }^{1}$, \\ Elma Yulius ${ }^{1}$, Ninik Paryati ${ }^{1}$, Fajar Prihesnanto ${ }^{1}$ \\ ${ }^{1}$ FakultasTeknik, Universitas Islam 45; Jl. Cut Meutia No. 83 Bekasi, Telp: (021) 8808851; \\ email: ekodarma91@gmail.com, anita_ft@unismabekasi.ac.id, dianeka1219@gmail.com, \\ inna.ekawati@gmail.com,srinuryati45ft@gmail.com,elmayulius@gmail.com, \\ nparyati@yahoo.com, tekniksipil@unismabekasi.ac.id \\ *Korespondensi: e-mail: anita_ft@unismabekasi.ac.id
}

Submitted: 11/05/2021; Revised: 09/06/2021; Accepted: 15/06/2021; Published: 28/06/2021

\begin{abstract}
This activity aims to provide services and information to the manager of the Nuurus Sa'ada mosque in assessing the compressive strength of the concrete at the renovation of the Nurus Sa'ada Tangerang mosque as a quality control for the building being renovated. The method of activity is to do the Hammer test at several points in the Mushola area such as the floor plate and column structures. This activity involved lecturers in Universitas Islam 45, Faculty of Engineering, Universitas Islam 45 Civil Engineering laboratory assistants, and the manager of the Nurus Sa'ada mosque, as well as renovation implementers.
\end{abstract}

Key words: Hammer Test, Mushola Renovation, Compressive Strength, Mosque

\begin{abstract}
Abstrak
Kegiatan ini bertujuan untuk memberikan pelayanan dan informasi kepada pengelola mushola Nuurus Sa'ada untuk menilai kuat tekan beton pada renovasi mushola Nurus Sa'ada Tangerang sebagai kontrol kualitas bangunan yang sedang direnovasi. Metode kegiatan yaitu dengan melakukan pengujian Hammer test di beberapa titik area Mushola seperti pada struktur plat lantai dan kolom. Kegiatan ini melibatkan para dosen di lingkungan Fakultas Teknik Universitas Islam 45, laboran Teknik Sipil Universitas Islam 45, dan pengelola Mushola Nurus Sa'ada, serta pelaksana renovasi.
\end{abstract}

Kata kunci: Hammer Test, Renovasi Mushola, Kuat Tekan, Beton

\section{Pendahuluan}

Mushola Nurus Sa'adah berdiri pada tahun 1989 oleh Bapak Haji Nawi yang diperuntukkan bagi warga sekitar, di kecamatan Larangan Selatan, Ciledug Tangerang. 3 bulan sebelum pembangunan renovasi, Mushola Nurus Sa'adah ini mengalami konsleting listrik sehingga menyebabkan kebakaran.

Dalam pembangunan renovasinya, mushola tidak sepenuhnya dirobohkan, ada beberapa bagian struktur bangunan lama yang masih kokoh dan dapat digunakan sebagaimana fungsi dari struktur bangunan tersebut. Oleh karena itu, perlu adanya penilaian kuat tekan beton pada struktur beton lama maupun struktur beton baru untuk membantu mengevaluasi pembangunan renovasi mushola Nurus Sa'adah ini agar memperoleh tingkat kelayakan struktur 
yang sesuai standar, baik pada beton baru maupun beton lama. Untuk mendapatkan informasi mengenai tingkat keamanan struktur dari suatu komponen bangunan ataupun bangunan secara keseluruhan akibat adanya faktor-faktor yang tidak diperhitungkan sebelumnya diperlukan pengujian-pengujian. Ada beberapa bentuk metode pengujian yang dapat digunakan untuk menentukan kelayakan suatu struktur. Uji kelayakan yang dilakukan untuk menentukan kapasitas bangunan terutama struktur kolom dan balok dalam memikul beban yang bekerja pada bangunan serta rekomendasi renovasi yang dapat dilakukan terhadap bangunan tersebut. Uji kelayakan bangunan menggunakan Hammer tes pernah dilakukan (Nurhasanah et al., 2017), (Candra et al., 2019) dan (Amrulloh et al., 2016). Hasil uji kelayakan bangunan Mushola Nurus Sa'adah nantinya dapat memberikan jawaban apakah struktur bangunan tersebut masih layak atau tidak dalam memikul beban yang bekerja. Kegiatan pengabdian pada masyarakat terhadap struktur dan tata ruang masjid pernah dilakukan oleh (Sholeh et al., 2020), (Oroh et al., 2019), dan (Masrul et al., 2021).

Fakultas Teknik Universitas Islam 45 Bekasi pada periode sebelumnya telah melakukan program Pengabdian Masyarakat berupa pelaksanaan beberapa jenis pelatihan komputer (Hasad et al., 2020) dan (Paryanti et al., 2020) yang bertujuan untuk mengembangkan dan meningkatkan skill masyarakat. Pada era covid'19, pelaksanaan program pengabdian pada masyarakat mengalami adaptasi jaman melalui pelatihan online seperti yang dilakukan (Samsiana et al., 2020) dan (Khasanah et al., 2020).

Kegiatan pengabdian pada masyarakat kali ini dilaksanakan pada tanggal 2 Februari 2021 oleh dosen fakultas teknik universitas islam 45 Bekasi yang tergabung dalam kelompok Pengabdian Pada Masyarakat (PPM) 4 Fakultas Teknik, yaitu melakukan penilaian kuat tekan beton pada Struktur Mushola Nurus Sa'adah menggunakan Hammer tes secara offline dengan menjaga protokol kesehatan.

\section{Metode Pelaksanaan}

Pada tahap awal kegiatan pengabdian kepada masyarakat dilakukan melalui analisis situasi pada mushola Nurus Sa'adah. Analisis situasi dilakukan melalui komunikasi dengan pengelola Mushola dan tim pekerja pembangunan renovasi, untuk menentukan titik-titik uji yang diperlukan. Pada tahap persiapan ini juga, dilakukan koordinasi dengan tim pengabdian pada masyarakat untuk menentukan peralatan uji, gambar, dokumen dan lain lain untuk menyusun teknik pelaksanaan lapangan kegiatan.

Pelaksanaan kegiatan pengabdian kepada masyarakat berupa penilaian kuat tekan beton di Mushola Nurus Sa'adah ini, seluruh tim ikut terlibat dari awal pelaksanaan hingga akhir kegiatan. Tim PPM-4 Fakultas Teknik Universitas Islam 45 Bekasi diketuai oleh Eko Darma (Dosen Teknik Sipil) dengan Anggota kelompok yaitu: Dian Ekawati (Dosen Teknik Mesin), Inna Ekawati (Dosen Teknik Komputer), Sri Nuryati (Dosen Teknik Sipil), Elma Yulius (Dosen Teknik Sipil), Ninik Paryati (Dosen Teknik Sipil), Fajar Prihesnanto (Dosen Teknik Sipil), Anita Setyowati 
Srie Gunarti (Dosen Teknik Sipil), Tugiran (Laboran Teknik Sipil), Saprian Dani (Mahasiswa Teknik Sipil).

Pelaksanaan kegiatan dilakukan dengan malakukan penggambaran denah titik uji dan penentuan titik uji, kemudian dilakukan pengujian Hammer (Hammer test) di beberapa titik uji pada lantai dan kolom pada bangunan Mushola lantai 1 dan lantai 2. Data-data Hammer Test dicatat pada form uji yang telah disiapkan untuk kemudian dilakukan pengolahan data dan analisa. Laporan hasil uji penilaian kuat tekan beton Mushola Nurus Sa'adah yang telah selesai dibuat selanjutnya disosialisasikan kepada pengelola Mushola dan tim pekerja renovasi sekaligus pendampingan dan monitoring pembangunan renovasi Mushola. Kegiatan ini dilaksanakan dalam beberapa tanah seperti pada gambar 1 .

\section{Analisis Situasi:}

1. Komunikasi dengan pengelola mushola dan para pelaksana renovasi 2. Pengamatan visual

Persiapan:

1. Penentuan Teknik pelaksanaan

2. Koordinasi Tim pelaksana pengabdian masyarakat

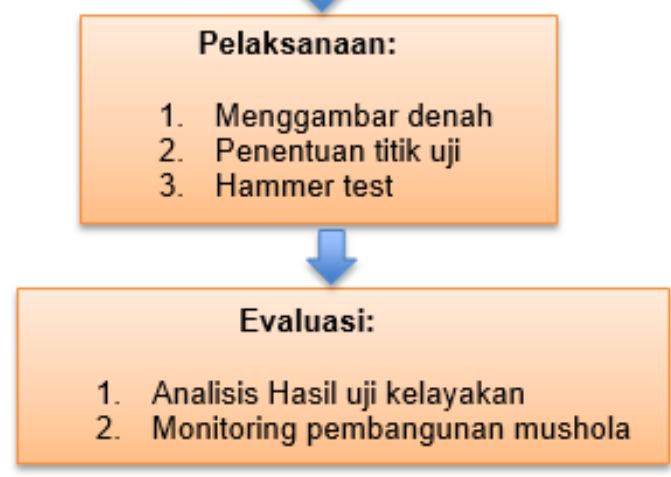

Sumber: Hasil Pelaksanaan (2021)

Gambar 1. Tahapan Pelaksanaan

\section{Hasil dan Pembahasan}

Mushola Nurus Sa'adah di renovasi menjadi 2 lantai bangunan. Pada struktur bangunan lama, Mushola Nurus Sa'adah ini tidak sepenuhnya dirobohkan. Beberapa bagian masih tetap dipertahankan utuh, terutama sebagian besar lantai 1. Sebagian besar kolom dan dinding pada lantai 1 dipertahankan, sedangkan bagian yang mengalami renovasi pada lantai 1 berada di area depan atau pintu masuk Mushola, dan beberapa bagian lain sebagai perluasan.

Dikarenakan bangunan ini sebelum renovasi mengalami kebakaran, maka permasalahan utama adalah kuat dukung yang berubah. Oleh karna itu, dilakukan penilaian kuat tekan tekan beton pada struktur bangunan lama dan juga bangunan baru untuk penentuan kelayakan kuat dukungnya. Tim Pengabdian Pada Masyarakat yang tergabung dalam kelompok 4 Fakultas 
Teknik Universitas Islam 45 Bekasi melakukan kegiatan pengabdian pada masyarakat yang dimulai dengan melakukan peninjauan visual seperti yang ditunjukkan pada Gambar 2. Peninjauan visual ini dilakukan untuk merencanakan atau penentuan titik uji pada lokasi yang paling dibutuhkan, baik pada struktur lama maupun struktur bangunan yang baru pembangunan renovasi Mushola Nurus Sa'adah.

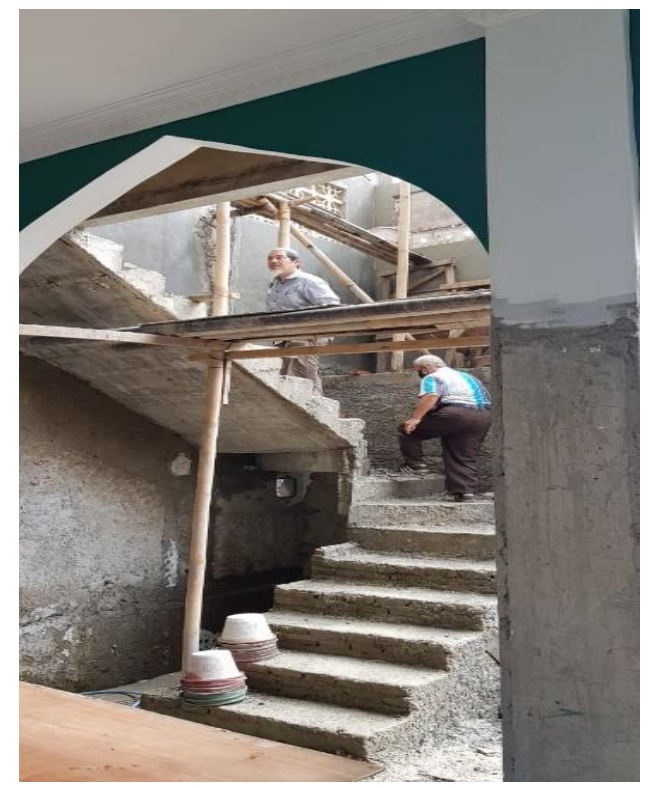

Sumber: Hasil Pelaksanaan (2021)

\section{Gambar 2. Pengamatan Visual}

Setelah peninjauan visual, dilanjutkan dengan penggambaran denah dan titik lokasi uji seperti yang ditunjukkan pada Gambar 3. Titik pengujian ditentukan pada lantai atas dan lantai lantai bawah Mushola di beberapa bagian kolom dan plat lantai.

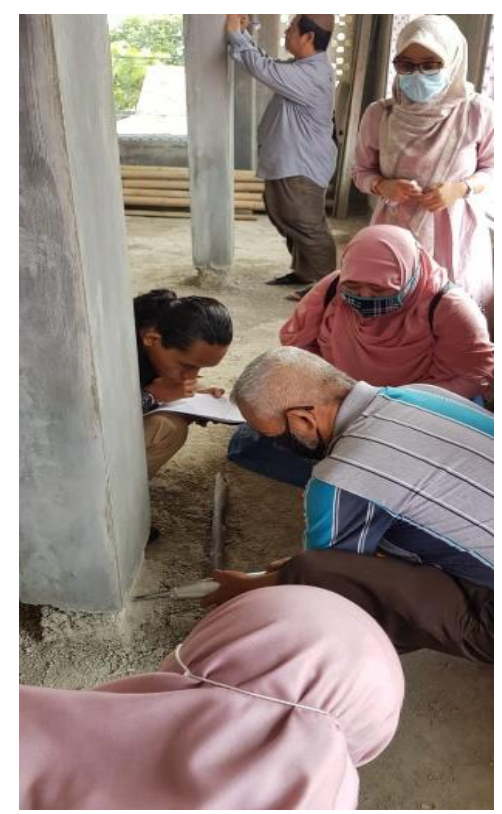

Sumber: Hasil Pelaksanaan (2021)

Gambar 3. Penggambaran Denah Struktur Dan Penentuan Titik Uji 
Pengambilan data hasil dari uji Hammer test dicatat pada Form pencatatan Hammer test yang telah disiapkan. Pengambilan data melalui hammer tes dilakukan di lantai 2 terlebih dulu pada kolom dan plat lantai seperti yang ditunjukkan pada Gambar 4.

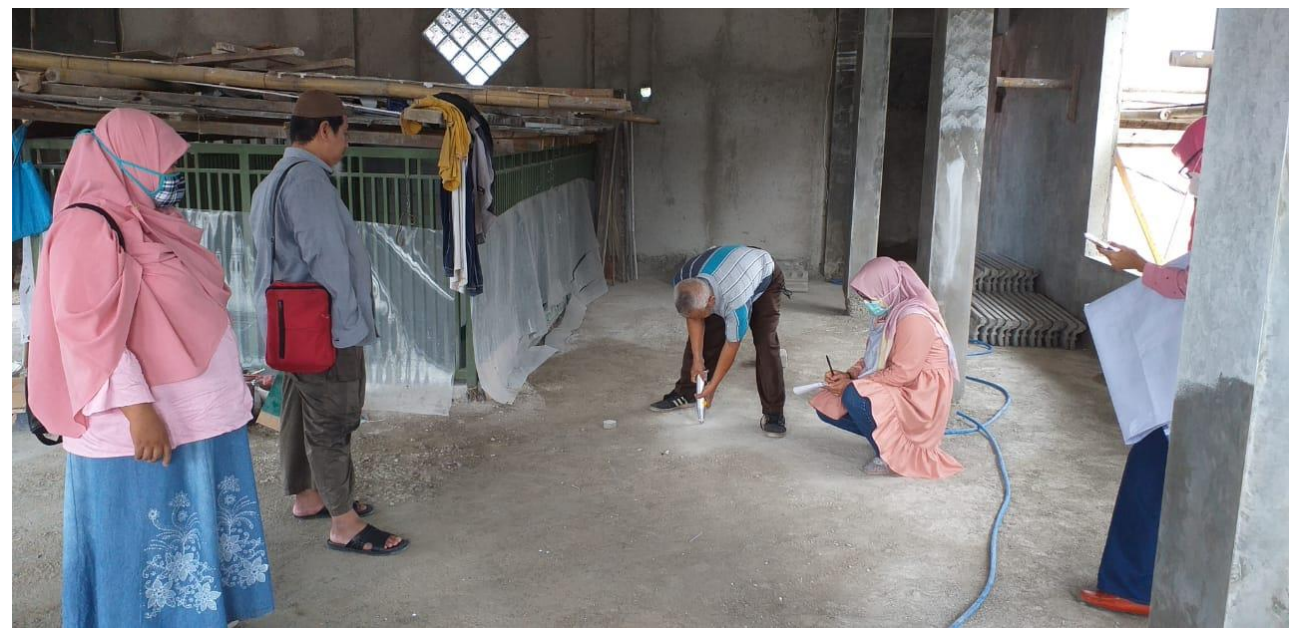

Sumber: Hasil Pelaksanaan (2021)

Gambar 4. Hammer Test Pada Plat Lantai Di Lantai 2

Setelah lantai 2 telah selesai pengambilan data melalui Hammer tes, dilanjutkan pengambilan data di lantai 1 pada kolom lama dan kolom baru seperti yang ditunjukkan pada Gambar 5.
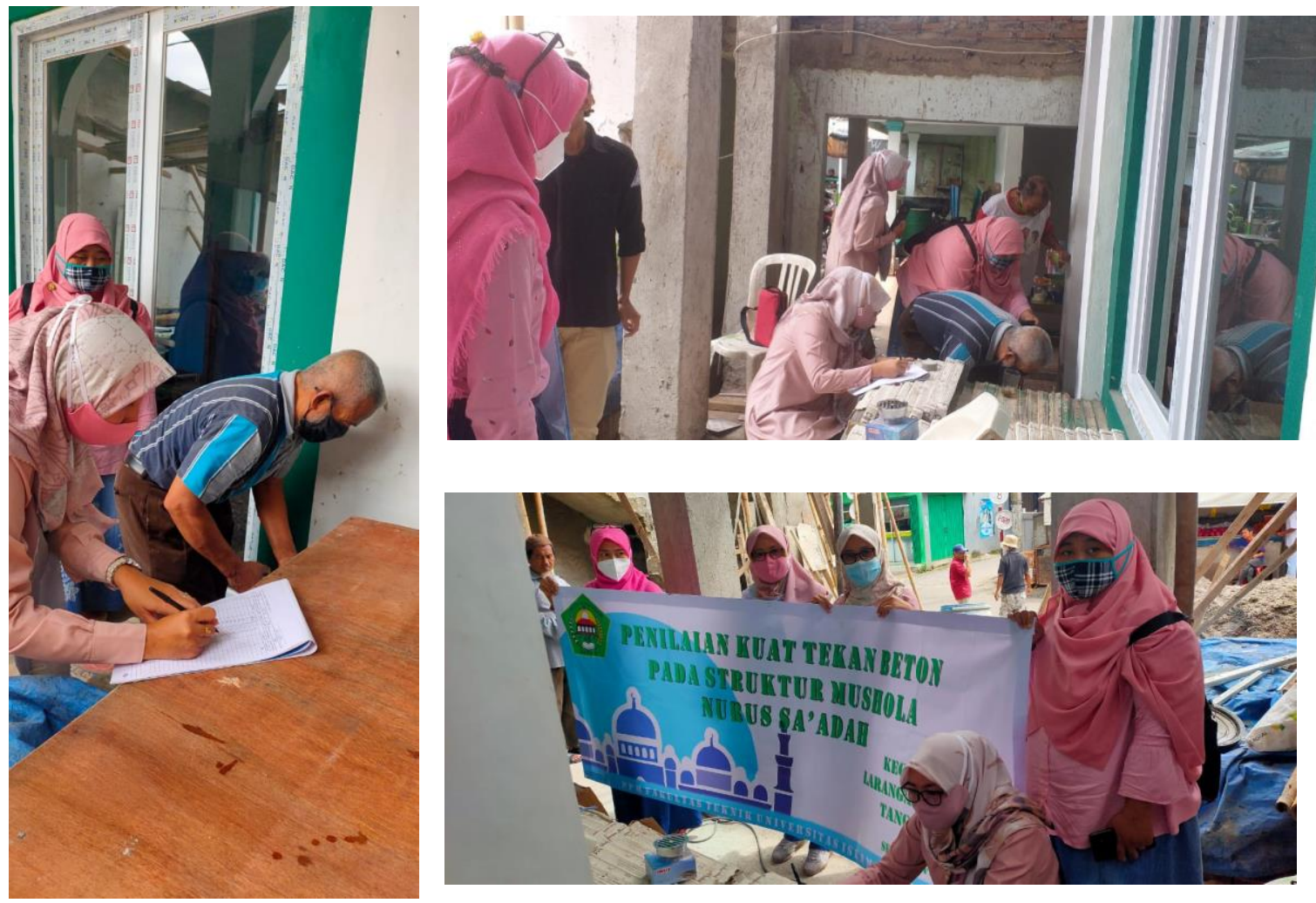

Sumber: Hasil Pelaksanaan (2021)

Gambar 5. Hammer Test Pada Kolom Lantai 1 
Eko Darma, Anita Setyowati Srie Gunarti, Dian Ekawati, Inna Ekawati, Sri Nuryati, Elma Yulius, Ninik Paryati, Fajar Prihesnanto

Pengambilan data kuat tekan beton melalui Hammer Test telah lengkap dicatat dan berjalan lancar (Gambar 6), selanjutnya dilakukan pengolahan data dan analisa hasil.

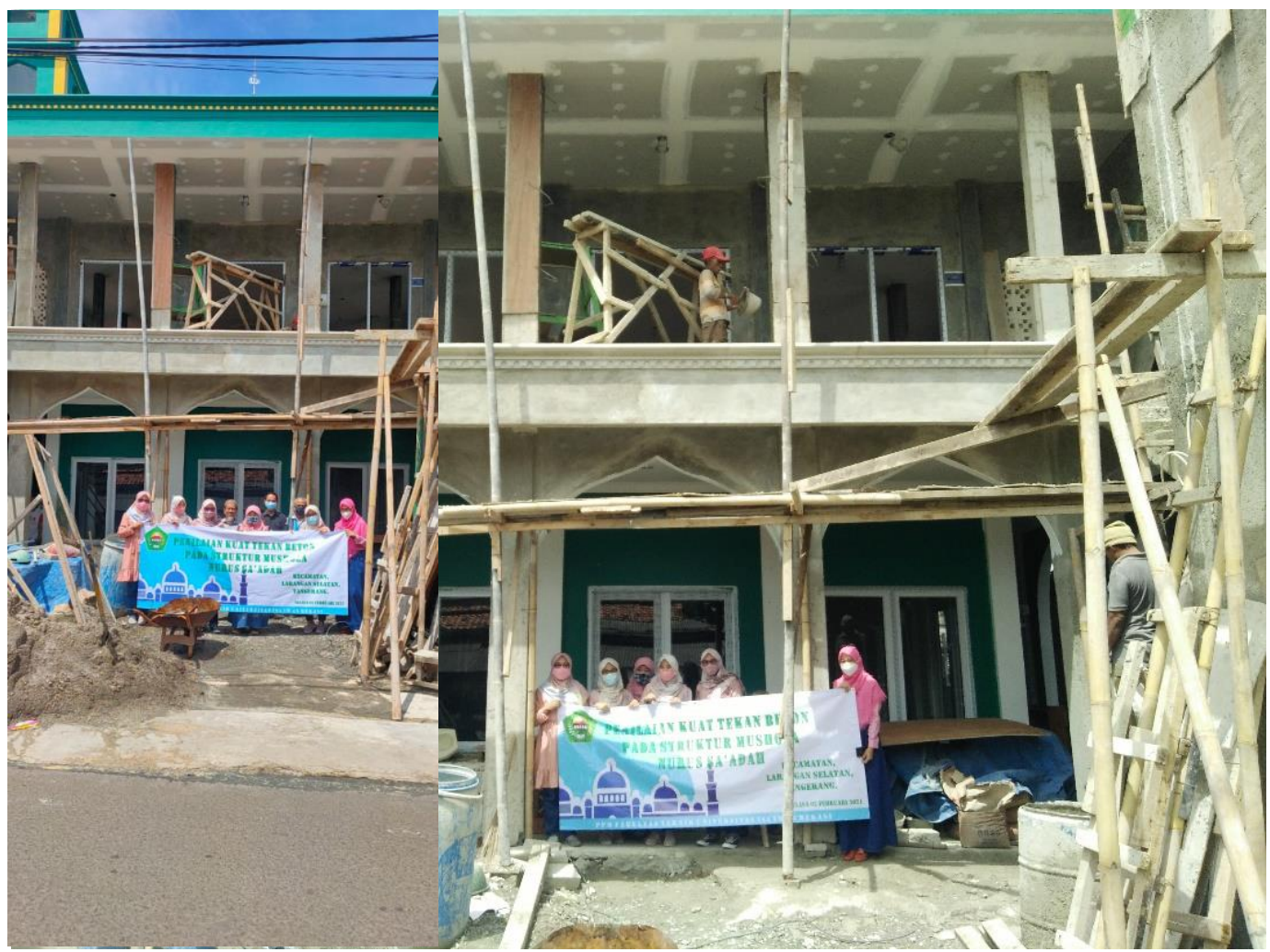

Sumber: Hasil Pelaksanaan (2021)

Gambar 6. Kegiatan Pengabdian Kepada Masyarakat Berjalan Lancar

Denah titik Hammer tes pada lantai 1 dan lantai 2 pembangunan renovasi Mushola Nurus Sa'adah ditunjukkan pada Gambar 7.

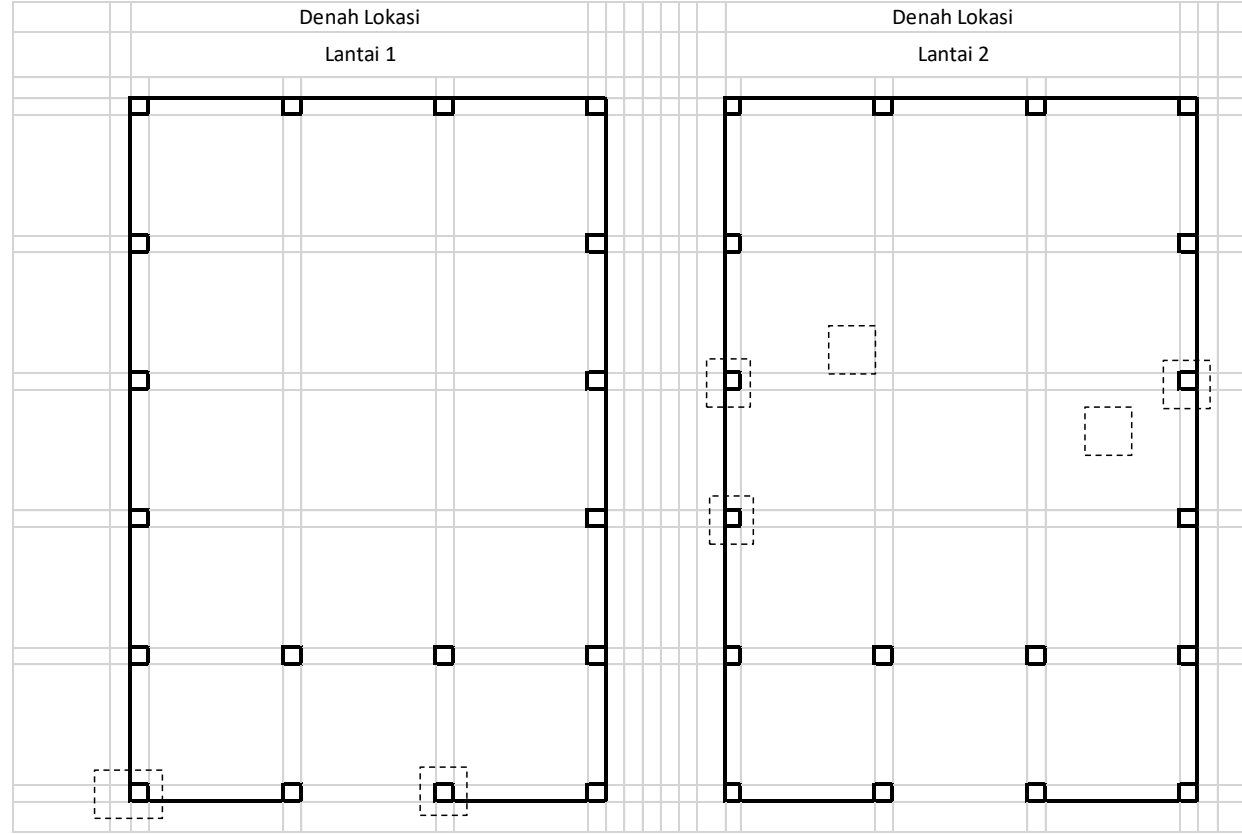

Sumber: Hasil Pelaksanaan (2021)

Gambar 7. Denah titik uji Hammer Test 
Data Hammer tes yang telah diperoleh kemudian dilakukan pengolahan dan perhitungan menggunakan Ms. Excell disajikan dalam Tabel 1.

Tabel 1. Hasil Uji Kuat Tekan Beton

\begin{tabular}{|c|c|c|c|c|c|c|c|c|c|c|c|c|c|c|}
\hline \multirow{2}{*}{$\begin{array}{l}\text { No. } \\
\text { Loka } \\
\text { si }\end{array}$} & \multicolumn{10}{|c|}{ ANGKA PANTUL ( R ) Mpa } & \multirow{2}{*}{$\begin{array}{l}\sum \mathrm{R} \\
(\mathrm{Mp} \\
\mathrm{a})\end{array}$} & \multirow{2}{*}{$\begin{array}{c}\text { Fakto } \\
r \\
\text { Korek } \\
\text { si } \\
\text { Alat }\end{array}$} & \multirow{2}{*}{$\begin{array}{c}\mathrm{R} \\
\text { Koreks } \\
\mathrm{i}(\mathrm{MPa})\end{array}$} & \multirow{2}{*}{$\begin{array}{c}\text { Mutu } \\
\text { Beton } \\
(\mathrm{K}) \\
\mathrm{Kg} / \mathrm{cm}^{2}\end{array}$} \\
\hline & 1 & 2 & 3 & 4 & 5 & 6 & 7 & 8 & 9 & 10 & & & & \\
\hline \multirow{2}{*}{1} & 23. & & & 33. & 28. & 31. & 28. & 26. & 31. & 31. & & 1.088 & 33.743 & 344.082 \\
\hline & 4 & 35 & 35 & 4 & 2 & 6 & 2 & 4 & 6 & 6 & 31 & 5 & 5 & 47 \\
\hline \multirow{2}{*}{2} & 23. & 26. & 21. & 26. & 21. & 21. & 28. & 23. & 21. & 24. & 23.8 & 1.088 & 25.993 & 265.054 \\
\hline & 4 & 4 & 6 & 4 & 6 & 6 & 2 & 4 & 6 & 8 & 8 & 5 & 38 & 5 \\
\hline \multirow{2}{*}{3} & 21. & 23. & 21. & 28. & 28. & & 26. & 23. & 21. & 21. & & 1.088 & 26.777 & 273.046 \\
\hline & 6 & 4 & 6 & 2 & 2 & 20 & 4 & 4 & 6 & 6 & 24.6 & 5 & 1 & 09 \\
\hline \multirow{2}{*}{4} & 18. & 21. & 23. & & 18. & 18. & 18. & & 18. & 21. & 19.6 & 1.088 & 21.378 & 217.992 \\
\hline & 6 & 6 & 4 & 16 & 6 & 6 & 6 & 20 & 6 & 6 & 4 & 5 & 14 & 89 \\
\hline \multirow{2}{*}{5} & 23. & & 21. & & 18. & 17. & 18. & 21. & 18. & & 20.7 & 1.088 & 22.553 & 229.980 \\
\hline & 4 & 20 & 6 & 20 & 6 & 2 & 6 & 6 & 6 & 20 & 2 & 5 & 72 & 28 \\
\hline \multirow{2}{*}{6} & & 16. & & & 15. & 19. & & 16. & 16. & 19. & 16.4 & 1.088 & 17.894 & 182.474 \\
\hline & 14 & 8 & 18 & 18 & 4 & 4 & 18 & 8 & 8 & 4 & 4 & 5 & 94 & 7 \\
\hline \multirow{2}{*}{7} & & 15. & & & & & & & 16. & & & 1.088 & & \\
\hline & 14 & 4 & 14 & - & 14 & - & - & - & 8 & 15 & - & 5 & - & - \\
\hline
\end{tabular}

Sumber: Hasil Pelaksanaan (2021)

Dari Hasil pengolahan data tersebut maka diperoleh hasil bahwa seluruh titik uji dinyatakan sesuai rencana (memenuhi syarat).

\section{Kesimpulan}

Kegiatan penilaian kuat tekan beton pada Mushola Nurus Sa;adah yang telah dilakukan oleh tim PPM4 Fakultas Teknim Universitas Islam 45 Bekasi berfokus pada pelayanan penilaian kelayakan bangunan renovasi. Luaran dari kegiatan ini adalah laporan hasil kuat tekan beton struktur bangunan Mushola urus Sa'adah. Analisa yang didapatkan dari data uji Hammer test pada struktur bangunan Mushola Nurus Sa'adah ini adalah baik kolom maupun plat lantai sesuai syarat keamanan dan sesuai rencana. Dengan adanya kegiatan ppm berupa penilaian kuat tekan beton pada struktur bangunan renovasi Mushola Nurus Saadah ini maka dapat memudahkan monitoring kelayakan mutu bangunan bagi pengelola Mushola dan tim pekerja renovasi sehingga bangunan yang sedang dikerjakan memenuhi syarat standar keamanan struktur.

\section{Ucapan Terima Kasih (Opsional)}

Tim Pengabdian Pada Masyarakat kelompok 4 Fakultas Teknik Universitas Islam 45 Bekasi mengucapkan terimakasih kepada mitra yaitu pengelolas Mushola Nurus Sa'adah yang 
telah bersedia menjadi mitra dalam pengabdian masyarakat ini. Semoga apa yang telah dilakukan dapat memberikan manfaat bagi kedua pihak

\section{Daftar Pustaka}

Amrulloh, A. R., Darma, E., \& Gunarti, A. S. S. (2016). Perencanaan Struktur Beton Bertulang Gedung Sekolah SMK Pembangunan Nasional Al-Muhyiddin Kec. Banjarsari, Ciamis, Jawa Barat. BENTANG: Jurnal Teoritis dan Terapan Bidang Rekayasa Sipil, 4(2), 14-29.

Candra, A. I., Poernomo, Y. C. S., Ridwan, A., Winarto, S., Gardjito, E., \& Siswanto, E. (2019). Pengecekan Kelayakan Bangunan Gedung Sma Negeri 1 Kota Kediri Yang Digunakan Untuk Aktifitas Belajar. Jurnal Abdi Masyarakat, 2(2).

Hasad, A., \& Yulius, E. (2020). Pengembangan Peran Pemberdayaan Masyarakat Berbabis Komunitas. DEVOSI, 1(2), 28-31.

Khasanah, F. N., Samsiana, S., Handayanto, R. T., Gunarti, A. S. S., \& Raharja, I. (2020). Pemanfaatan Media Sosial dan Ecommerce Sebagai Media Pemasaran Dalam Mendukung Peluang Usaha Mandiri Pada Masa Pandemi Covid 19. Jurnal Sains Teknologi dalam Pemberdayaan Masyarakat, 1(1), 51-62.

Masrul, W., \& Samra, B. (2021). Efektifitas Pola Tata Ruang Terhadap Sistim Sirkulasi Mesjid AIMukarramah-Pekanbaru. COMSEP: Jurnal Pengabdian Kepada Masyarakat, 2(1), 38-45.

Nurhasanah, A., Yulfriwini, Y., Susilowati, S., Juniardi, J., \& Sadad, I. (2017). Kajian Kelayakan Struktur Gedung Pasar Cendrawasih Kota Metro. Pengabdian Kepada Masyarakat, (2).

Oroh, R. R. (2019). Penerapan Teknologi Mix Design Beton Pada Peningkatan Keterampilan Para Tukang Bangunan. Abdimas: Jurnal Pengabdian Kepada Masyarakat, 12(3), 251258.

Paryanti, N., Irwan, D., Samsiana, S., Nugroho, R., Gunarti, A. S., Rokhman, T., \& Paronda, A. H. (2020). Kerjasama Kemitraan, Pelatihan Aplikasi Teknologi Informasi Dan Komunikasi. DEVOSI, 1(1), 10-13.

Samsiana, S., Handayanto, R. T., Gunarti, A. S. S., Raharja, I., Khasanah, F. N., Herlawati, H., \& Benrahman, B. (2020). Optimasi Penggunaan Android Sebagai Peluang Usaha Di Masa Pandemik COVID'19. Jurnal Pengabdian kepada Masyarakat UBJ, 3(2), 137-148.

Sholeh, M. N., Lukman, L., Hartono, H., \& Suwarto, F. (2020). Perencanaan Struktur Renovasi Masjid Darussalam Semarang dengan Structure Analysis Program. Jurnal Pengabdian Vokasi, 1(4), 237-241. 